\title{
Neonatal hearing screening: the importance of the study of risk indicators for hearing loss
}

\begin{abstract}
Objective: to analyze the frequency of risk indicators for hearing loss and its influence on the increase number of refer cases. Methodology: The study was carried out in a public hospital with a sample of 796 infants who participated in the neonatal hearing screening program by transient evoked otoacoustic emission (TEOAE). Results: $132(16 \%)$ newborn had some risk indicators for hearing loss. NICU stay, low Apgar score, mechanical ventilation, lower birth weight less than $1500 \mathrm{~g}$ and use of ototoxic drugs were the most frequenty risk indicators. A total of $51(6 \%)$ newborns refer in the TEOAE test in at least one ear, and among them, $16(31 \%)$ had a risk indicator for hearing loss. There was a statistically significant relationship between the refer rates in TEOAE with the following risk indicators: craniofacial malformation, genetic syndrome and birth weight less than $1500 \mathrm{~g}$. Conclusion: The NICU stay, low Apgar score, mechanical ventilation, birth weight less than $1500 \mathrm{~g}$ and use of ototoxic drugs were the risk indicators most frequenty in this sample and the main risk indicator associated with refer in the TEOAE teste were craniofacial malformations, genetic syndromes and birth weight less than $1500 \mathrm{~g}$.
\end{abstract}

Keywords: risk indicators, newborn, hearing loss
Volume 8 Issue 3 - 2017

\author{
Georgea Espindola Ribeiro, Jair Cortez \\ Montovani, Daniela Polo Camargo da Silva \\ Faculdade de Medicina de Botucatu Universidade Estadual \\ Paulista, Bazil
}

Correspondence: Daniela Polo Camargo da Silva Faculdade de Medicina de Botucatu Universidade Estadual Paulista UNESP CEP I86I8687 Botucatu, Brazil, Tel 55(|4) 381 I-6256, Email Daniela-polo@uol.com.br

Received: June 23, 2017| Published: August 09, 2017

\section{Introduction}

The prevalence of bilateral congenital hearing loss is 1 to $3 / 1000$ live births, and in neonates with risk indicators for hearing, especially those coming from the Neonatal Intensive Care Unit (NICU), this prevalence increases 20 to 50/1000 live births. ${ }^{1,2}$

Hearing is an important sense for the development of speech and language, therefore the earlier the hearing loss is detected, the greater is the chances of promoting the development of oral language close to that of normal hearing individuals. ${ }^{3,5}$

Neonatal hearing screening allows identification of those who present a probable deafness before hospital discharge and the knowledge of the population characteristics to be screened supports to guide the cases.

When the risk indicators for hearing loss is present it is necessary that the neonate be monitored audiologically, sequentially, in the first years of life, because the hearing loss can occur late and consequently affect the maturation of the auditory system, which has an unfavorable effect on the language acquisition process. ${ }^{6,7}$

Therefore, it should be emphasized that the assessment of risk indicators for hearing is done in the maternity which will allow the elaboration of auditory attention protocols, providing the creation of actions to prevent and promote hearing health. ${ }^{8,9}$

The objective of this study was to analyze the frequency of risk indicators for hearing loss and its influence on the increase number of refer cases.

\section{Methodology}

It was a cross-sectional retrospective clinical study, conducted from January 2014 to December 2014, in a tertiary referral center. The Ethical Committee of the hospital approved the study (protocol $3395 / 09$ ). Information on the pre, peri and postnatal history of the patients was collected through medical records, as well as the results of neonatal hearing screening.
The inclusion criterion were: having been born in the maternity hospital of the study, participated in the neonatal hearing screening program and informed consent signed by the parents.

The risk indicator for hearing loss stated in the international guidelines $(\mathrm{JCIH})^{7}$ were investiged for all neonate.

The assessment was performed in all babies, with $48 \mathrm{hs}$ or up to 30days of life, with the infant in the state of natural sleep in the lap of the mother or in the cradle of the unit. The hearing screning was performed by transient evoked otoacoustic emission (TEOAE) registred by OtoRead/Interacoustic.

A bimodal statistical test gives automatically a response score ("pass" or "refer"). The TEOAE were elicited following nonlinear click sequence at $83 \mathrm{~dB}$ SPL, generated by a small probe positioned in the external canal, the sounds emitted bu active mechanical processes in the outer hair cells are recorded by microphone included in the probe. The values considered as "pass" were: emissions present at a signalto-noise ratio of $6 \mathrm{~dB}$ in at least three consecutive frequency bands, including $4000 \mathrm{~Hz}$. The capture time of the exam was a maximum of 64 seconds. The statistical analyses were performed using the multiple logistic regression test and the significance set at $\mathrm{p}<0.05$.

\section{Results}

Between the period of the study, a total of 796 newborn attempted the inclusion criteria and 382 (48\%) were female and 414 (52\%) were male. At least $132(16 \%)$ newborns had one risk indicator for hearing loss and $161(20 \%)$ were born preterm.

Among newborns at risk, we observed that 81 (61\%) had only one risk, while $51(39 \%)$ had two to six risks associated. Table 1 shows the frequency of risk indicators found in this study. A "refer" result in the TEOAE test was found in at least one ear of the $51(6 \%)$ neonates and among them, 16 (31\%) had an indicator for hearing loss.

No association were found between "refer" in the TEOAE test and the risk indicators such as: Low Apgar score, NICU stay > 48hours 
in, use of mechanical ventilation for more than 5 days, use of ototoxic drugs, occurrence of meningitis, syphilis and congenital toxoplasmosis, mothers using illicit drugs in pregnancy, hyperbilirubinemia, and family history of hearing loss. However, craniofacial malformations, genetic syndromes and birth weight less than $1500 \mathrm{~g}$ significantly increased the chances of "refer" in the TEOAE test (Table 2).

Table I Risk indicators for hearing loss in the sample

\begin{tabular}{lll}
\hline Variable & $\mathbf{n}$ & $\%$ \\
\hline Low Apgar & 52 & 6.5 \\
Birth weight < I500g & 24 & 3 \\
NCIU stay & 67 & 8.4 \\
Mechanical Ventilation & 30 & 3.8 \\
Ototoxic Drug & 22 & 2.7 \\
Miningitis & 6 & 0.8 \\
Congenital Syphilis & 9 & 1.1 \\
Congenital Toxoplasmosis & 5 & 0.6 \\
HIV & 4 & 0.5 \\
Craniofacial Malformation & 5 & 0.6 \\
Genetic Syndrome & 3 & 0.4 \\
Hyperbilirubinemia & 2 & 0.3 \\
Hearing loss in the Family & 1 & 0.1
\end{tabular}

Table 2 Logistic model adjusted to explain the TEOAE refer due to the risk indicators

\begin{tabular}{llllllll}
\hline Variable & $\boldsymbol{\beta}$ & ep & Wald & $\mathbf{p}$ & OR & \multicolumn{2}{l}{ IC(OR;95\%) } \\
\hline Low Apgar & 0.38 & 0.53 & 0.52 & 0.473 & 1.47 & 0.52 & 4.16 \\
$\begin{array}{l}\text { Birth Weight } \\
<1500 \mathrm{~g}\end{array}$ & 2.16 & 0.93 & 5.38 & 0.02 & 8.67 & 1.4 & 53.81 \\
NCIU & 0.22 & 0.68 & 0.11 & 0.744 & 1.25 & 0.33 & 4.71 \\
$\begin{array}{l}\text { Mechanical } \\
\text { Ventilation }\end{array}$ & -1.64 & 1.08 & 2.31 & 0.128 & 0.19 & 0.02 & 1.61 \\
$\begin{array}{l}\text { Ototoxic } \\
\text { Drug }\end{array}$ & 0.5 & 0.93 & 0.29 & 0.593 & 1.65 & 0.26 & 10.22 \\
$\begin{array}{l}\text { Miningitis } \\
\text { Craniofacial }\end{array}$ & 0.51 & 1.32 & 0.15 & 0.698 & 1.67 & 0.13 & 22.09 \\
$\begin{array}{l}\text { Malformation } \\
\text { Genetic }\end{array}$ & 4.34 & 1.17 & 13.67 & 0 & 76.76 & 7.69 & 766.27 \\
$\begin{array}{l}\text { Syndrome } \\
\text { Constant }\end{array}$ & 3.37 & 1.28 & 6.97 & 0.008 & 29.2 & 2.39 & 357.23 \\
& -2.93 & 0.17 & 293.05 & 0 & 0.05 & &
\end{tabular}

\section{Discussion}

This study aimed to identify the occurrence and the influence of risk indicators for hearing loss in neonatal hearing screening.

The NICU stay and low Apgar score at birth were the most frequent risk indicators. Other authors observed a higher frequency of ototoxic medication use, family history of hearing loss, low Apgar score, hyperbilirubinemia and NICU stay. ${ }^{9-11}$ Therefore, the frequent heterogeneity of risk indicators in several studies in a population to be screened justifies the importance of this identification in each hearing health program.

In our sample, $16 \%$ of the newborns had at least one risk indicator hearing loss, while other authors showed a $56 \%$ and $12 \%$ of occurrence. ${ }^{10,12}$ These discrepancies occur mainly due to the difference in profile and the care type at each screening place.

It is common to observe that the presence of risk for hearing loss increases the chances of failure in hearing screening. Some studies reported a refer rate at $62.5 \%$ in infants with risk for hearing loss, while other show a lower refer rate at $17 \% .^{13,14}$ This variability may be a result of the population characteristics that were screened in each study, and depending on the risk associated with those children, the failure may be greater.

In this study, the craniofacial malformations, genetic syndromes and birht weight less than $1500 \mathrm{~g}$ showed the highest number of refer rates in the hearing screening. Other studies showed a greater number of refer rates in newborns with prolonged stay in the NICU, use of mechanical ventilation and use ototoxic medications, in neonates with a family history of hearing loss and in those with a low Apgar score. ${ }^{8,15,16}$

The increase number of refer in newborns with craniofacial malformations can be justified by the fact that these alterations are related to malformation of the hearing system and nervous system. ${ }^{16,17}$

The low birth weight has influenced the increased number of refer rates in TEOAE may be the fact that these newborns often have several other risk indicators associated including the use of ototoxic drugs and prematurity. ${ }^{18}$

Lastly, the identification of the frequency of risk indicators, as well as their influence, in hearing screening programs allows the adoption of appropriate assessment protocols and guidance of the team involved in the screening and diagnosis of hearing loss, as well as in the elaboration of follow-up programs of hearing health.

\section{Conclusion}

The most frequent risk indicators in this study were: prolonged ICU stay, low Apgar score, mechanical ventilation, birth weight less than $1500 \mathrm{~g}$ and use of ototoxic drugs.

Craniofacial malformations, genetic syndromes, and birth weight of less than $1500 \mathrm{~g}$ significantly increased the chances of refer in TEOAE test.

\section{Acknowledgments}

None.

\section{Conflicts of interest}

Author declares there are no conflicts of interest.

\section{Funding}

None.

\section{References}

1. Meyer C, Witte J, Hildmann A, et al. Neonatal screening for hearing disorders in infants at risk: incidence, risk, factors and follow-up. Pediatrics. 1999;104:900-904.

2. Lewis DR, Marone SAM, Mendes BCA, et al. Multiporfessional committee on auditory health: COMUSA. Braz J Otorhinolaryngol. 2010;76(1):121-128.

3. Stacey L. Children with hearing loss: developing listening and talking, birth to six, 3rd edition. Int J Audiol. 2017;56(5):358-359.

4. Khairi MD, Din S, Shahid H, et al. Hearing screening of infants in neonatal unit, Hospital Universiti Sains Malaysia using transient evoked otoacoustic emissions. J Laryngol Otol. 2005;119(9):678-683.

5. Yoshinaga-Itano C, Sedey AL, Coulter DK, et al. Language of early-and lateridentified children with hearing loss. Pediatrics. 1988;102(5):1161-1171 
6. Dorling JS, Field DJ. Follow up of infants following discharge from the neonatal unit: structure and process. Early Hum Dev. 2006;82(3):151-156.

7. American Academy of Pediatrics, Joint Committee on Infant Hearing. Year 2007 position statement: principles and guidelines for early hearing detection and intervention programs. Pediatrics. 2007;120(4):898-921.

8. Ohl C, Dornier L, Czajka C, et al. Newborn hearing screening on infants at risk. Int J Pediatr Otorhinolaryngol. 2009;73(12):1691-1695.

9. Amado BCT, Almeida EOC, Berni PS. Prevalence of deafness risk indicators in newborn in a São Paulo' upcountry maternity hospital. Rev CEFAC. 2009;11(1):18-23.

10. Bielecki I, Horbulewicz A, Wolan T. Risk factors associated with hearing loss in infants: an analysis of 5282 referred neonates. Int $J$ Pediatr Otorhinolaryngol. 2011;75(7):925-930.

11. Poonual W, Navacharoen N, Kangsanarak J, et al. Risk factors for hearing loss in infants under universal hearing screening program in Northern Thailand. J Multidiscip Healthc. 2015;9:1-5.

12. Rai N, Thakur N. Universal screening of newborns to detect hearing impairment -Is it necessary? International. Journal of Pediatric Otorhinolaryngology. 2013;77(16):1036-1041.
13. Lima MCMP, Rossi TRF, Françozo MFC, et al. Detection of hearing loss in neonates of a public hospital. Rev Soc Bras Fonoaudiol. 2010;15(1):1-6.

14. Faistauer M, Augusto TAM, Floriano M, et al. Implementation of a program of universal newborn hearing screening in a university hospital in a city in south Brazil: preliminary results. Revista da AMRIGS. 2012;56(1):22-25.

15. De Capua B, De Felice C, Constantini D, et al. Newborn hearing screening by transient evoked otoacustic emissions: analysis of response as a function of risk factors. Acta Otorhinolaryngol Ital . 2003;23(1):16-20.

16. Pereira PKS, Martins AS, Vieira MR, et al. Newborn hearing screening program: association between hearing loss and risk factors. Pró-Fono. 2007;19(3):267-278.

17. Piromchai P, Kasemsiri $P$, Thanawirattananit $P$, et al. Congenital malformations of the inner ear: case series and review of the literature. J Med Assoc Thai. 2015;98(Suppl 7):S217-S224.

18. Segre CA. Prevalence of hearing loss in very low birth weight. J Pediatr (Rio J. 2003;79(2):103-104. 